\title{
Interventional nephrology: current status and clinical impact in Japan
}

\author{
Masato Ikeda $^{1}$ (D) Hiroyuki Terawaki ${ }^{2} \cdot$ Eiichiro Kanda $^{3} \cdot$ Maiko Furuya $^{1}$. \\ Yudo Tanno $^{1}$ - Masatsugu Nakao ${ }^{4} \cdot$ Yukio Maruyama $^{4} \cdot$ Masutaka Maeda $^{5}$. \\ Chieko Higuchi $^{6}$ - Tsutomu Sakurada ${ }^{7}$. Tomohiro Kaneko ${ }^{8}$ - Hiroaki Io ${ }^{9}$. \\ Koji Hashimoto ${ }^{10}$ - Atsushi Ueda ${ }^{11} \cdot$ Keita Hirano $^{12}$ - Naoki Washida ${ }^{13}$. \\ Hiraku Yoshida $^{14}$ - Kazuhiro Yoshikawa ${ }^{15}$. Yoshihiro Taniyama ${ }^{16}$. \\ Kenji Harada $^{17} \cdot$ Nanae Matsuo $^{4} \cdot$ Ichiro Okido $^{4} \cdot$ Takashi Yokoo $^{4}$
}

Received: 27 December 2016/Accepted: 25 July 2017/Published online: 2 August 2017

(c) The Author(s) 2017. This article is an open access publication

\begin{abstract}
Background Current status and clinical significance of interventional nephrology has not been reported from Japan.

Methods Questionnaires were mailed twice to the directors of all 534 Japanese certificated nephrology training institutions in 2014. The main questions were current performance, categorized annual procedure volume and managers of peritoneal dialysis (PD) access, vascular
\end{abstract}

Masato Ikeda

aoto-jinnai@jikei.ac.jp

1 Division of Nephrology and Hypertension, The Jikei University School of Medicine Katsushika Medical Center, 6-41-2 Aoto, Katsushika-ku, Tokyo 125-8506, Japan

2 Dialysis Center, Fukushima Medical University Hospital, 1 Hikariga-oka, Fukushima 960-1295, Japan

3 Department of Nephrology, Tokyo Kyosai Hospital, 2-3-8 Nakameguro, Meguro-ku, Tokyo 153-8934, Japan

4 Division of Nephrology and Hypertension, Department of Internal Medicine, Jikei University School of Medicine, 3-258 Nishi-shinbashi, Minato-ku, Tokyo 105-8461, Japan

5 Nephrology Division, Department of Internal Medicine, JA Toride Medical Center, 2-1-1 Hongo, Toride, Ibaraki 302-0022, Japan

6 Division of Internal Medicine, Tokyo Women's Medical University Medical Center East, 1-10-2 Nishiogu, Arakawa-ku, Tokyo 116-8567, Japan

7 Division of Nephrology and Hypertension, Integrated Care Center for Kidney Disease, St. Marianna University School of Medicine, 2-16-1 Sugao, Miyamae-ku, Kawasaki, Kanagawa 216- 8511, Japan

8 Division of Nephrology, Department of Internal Medicine, Nippon Medical School, 1-1-5 Sendagi, Bunkyo-ku, Tokyo 113-8603, Japan access (VA) surgery, endovascular intervention, and kidney biopsy. Frequencies of nephrologist involvement between high volume center and low volume center and association between the level of nephrologists' involvement to each procedure and annual procedure volume were examined.

Results 332 (62.2\%) institutions answered performance of all procedures and $328(61.4 \%)$ institutions answered all procedure volume. Kidney biopsy, VA surgery, endovascular
9 Division of Nephrology, Department of Internal Medicine, Juntendo University Faculty of Medicine, 2-1-1 Hongo, Bunkyo-ku, Tokyo 113-8421, Japan

10 Department of Nephrology, Shinshu University School of Medicine, 3-1-1 Asahi, Matsumoto, Nagano 390-8621, Japan

11 Tsukuba University Hospital Hitachi Medical Education and Research Center, Jonan-cho 2-1-1, Hitachi, Ibaraki 317-0077, Japan

12 Division of Nephrology, Department of Internal Medicine, Ashikaga Red Cross Hospital, 284-1 Yobe-cho, Ashikaga, Tochigi 326-0843, Japan

13 Department of Endocrinology, Metabolism and Nephrology, Keio University School of Medicine, 35 Shinanomachi, Shinjyuku-ku, Tokyo 160-8582, Japan

14 Hiraku Clinic, 5-18-9 Kamisoshigaya, Setagaya-ku, Tokyo 157-0065, Japan

15 Department of Nephrology, Iwate Prefectural Central Hospital, 1-4-1 Ueda, Morioka-shi, Iwate 020-0066, Japan

16 Department of Nephrology, Kinki University School of Medicine, 377-2 Ohno-higashi, Osakasayama-shi, Osaka 589-8511, Japan

17 Division of Nephrology, Kokura Memorial Hospital, 3-2-1 Asano, Kokurakita-ku, Kitakyushu-shi, Fukuoka 802-8555, Japan 
intervention and PD access surgery were performed by any doctors in $94.2,96.3,88.4$, and $76.2 \%$ and each involvement of nephrologist was 93.9, 54.1, 53.1 and 47.6\%, respectively. Cochran-Armitage analyses demonstrated significant increases in all 4 procedure volume with greater management by nephrologists $(p<0.01)$. Nephrologists involvement to VA surgery associated with procedure volume increase in not only VA surgery, but also PD catheter insertion $(p<0.01)$ and kidney biopsy $(p<0.05)$. And nephrologists involvement to PD catheter insertion also associated with surgical volume increase in both VA surgery $(p<0.01)$ and endovascular intervention $(p<0.05)$.

Conclusions Main manager of all 4 procedures was nephrologist in Japan. Each procedure volume increased as nephrologists become more involved. Acquisition of one specific procedure by nephrologist associated with increase not only in this specific procedure volume, but also the other procedure volume.

Keywords Nephrologist - Peritoneal · Dialysis · Vascular access $\cdot$ Endovascular $\cdot$ Kidney biopsy $\cdot$ Intervention

\section{Introduction}

Most fellows in non-nephrology internal medicine subspecialties have never considered nephrology as a career choice and the lack of procedural opportunities may be a major reason for not selecting nephrology as a career choice [1-3]. "Don't nephrologists perform any procedures?" medical students sometimes ask nephrologists not only in the United States [4], but also in Japan. In fact, nephrologists are managing ordinary dialysis therapy, though various non-nephrologists are performing procedures related to nephrology around the world. This fragmentation does not optimize medical care and may be inconvenient to the patient.

In 2000, the American Society of Diagnostic and Interventional Nephrology (ASDIN) was established to change the views of nephrologists regarding the practice of nephrology by promoting procedural aspects [4, 5]. Responding these actions, several countries have reported on the current status of interventional nephrology [6,7], but the exact proportions of procedures related to nephrology currently performed by nephrologists remains unclear [8]. Which doctors manage procedures related to nephrology and how many cases are performed in Japanese nephrology training institutions are unknown. Which specialties have positive effects on increasing case numbers are also unknown. If a certain procedure is performed by nephrologists, whether this has positive effects on the other procedure volume is likewise unclear.

No meetings comparable to ASDIN have been organized in Japan. We therefore, established the Japanese
Meeting for Interventional Nephrology in 2013, and conducted the first questionnaire survey of all 534 Japanese adult nephrology training institutions to clarify the actual conditions of interventions related to nephrology. This questionnaire asked what types and how many procedures were performed by what medical specialties in each hospital.

The results of this survey firstly demonstrated variability between institutions in the performance of procedures related to nephrology by various specialists in Japan, and revealed main managers of this field are nephrologists in Japan and procedure volume increases with increasing levels of involvement by nephrologists.

\section{Materials and methods}

\section{Methods}

The survey was written jointly by the authors based on their experience in clinical nephrology, performance and assessment of skills in nephrology-related procedures. The general distribution of case numbers for each procedure underwent preliminary field testing with 15 authors, all of whom were members of Japanese nephrology training institutions. Details of this survey were decided by the Japanese Meeting for Interventional Nephrology in July 2013 and February 2014. To improve response rates, we selected a minimal number of procedures for the present questionnaire and excluded placement of hemodialysis catheters from the present survey. The ethics committee for clinical research at Jikei University School of Medicine approved all protocols in this study [Permission no. 26-003 (7508)].

Certification in procedures for nephrology fellows in Japan requires that training in these skills be obtained in a nephrology training institution. We thus chose Japanese certificated adult nephrology training institutions as target institutions for this study. Questionnaires were mailed to the directors of all 534 Japanese nephrology training institutions at that time in July 2014. A follow-up questionnaire was posted again in November 2014. All responses were collected by fax.

The questionnaire comprised 4 sections, with questions about access procedures for peritoneal dialysis (PD) (PD catheters insertion, removal, and unroofing) [9, 10]; hemodialysis vascular access (VA) procedures (VA surgery and endovascular intervention) and kidney biopsy (Table 1).

\section{Data analysis}

Staff of the Japanese Meeting for Interventional Nephrology reviewed the questionnaires and developed the final analysis. 
Table 1 Questionnaire used in the present survey

1. Do you currently perform the procedures listed below at your institution?

[Peritoneal dialysis (PD) catheter insertion, removal and unroofing]

2. If yes, which specialists perform each procedure?

(1) Nephrologists

(2) Surgeons

(3) Urologists

(4) Others

3. If yes, how many cases are performed annually in your institution?

$<6,6-10,11-20,21-40,>40$

4. Do you currently perform vascular access (VA) surgery at your institution?

5. If yes, which specialists perform VA?

(1) Nephrologists

(2) Surgeons

(3) Cardiovascular surgeons

(4) Urologists

(5) Others

6. If yes, how many cases are performed annually in your institution?

$<11,11-50,51-150,151-300,>300$

7. Do you currently perform endovascular interventions at your institution?

8. If yes, which specialists perform endovascular interventions?
(1) Nephrologists
(2) Radiologists
(3) Surgeons
(4) Others

9. If yes, how many cases are performed annually in your institution?

$<11,11-50,51-150,151-300,>300$
Table 1 continued

10. Do you currently perform kidney biopsy at your institution?

11. If yes, which specialists perform kidney biopsies?

(1) Nephrologists

(2) Radiologists

(3) Urologists

(4) Others

12. If yes, how many cases are performed annually in your institution?

$<11,11-50,51-100,101-150,>150$

13. If yes, what methods are used for kidney biopsy in your institution?

(1) Percutaneous biopsy guided by ultrasound

(2) Percutaneous biopsy guided by X-ray

(3) Open biopsy (surgical biopsy)

(4) Others

\section{Institutional groupings}

We divided institutions into 3 groups: $\mathrm{N}$-institutions, with only nephrologists perform a specific procedure; non- $\mathrm{N}$ institutions, with only non-nephrologists performing the specific procedure; and C-institutions, with both nephrologists and non-nephrologists cooperatively performing the specific procedure.

\section{Statistics}

Statistical analyses were performed using JMP version 9.0 (SAS Institute, Cary, NC, USA). Data are expressed as mean \pm standard deviation or numbers and percentages of institutions. Comparisons across groups were performed using the Pearson's Chi-square test for categorical data. All tests were two-tailed, and values of $p<0.05$ were considered significant. Cochran-Armitage analysis was used to compare case numbers for procedures among the 3 groups of $\mathrm{N}$-institutions, non-N-institutions and $\mathrm{C}$-institutions. 
Table 2 Distribution of annual cases of key procedures

\begin{tabular}{|c|c|c|c|c|c|c|}
\hline \multicolumn{7}{|l|}{ VA surgery } \\
\hline Annual cases & $<11$ & $11-50$ & $51-150$ & $151-300$ & $>300$ & Total \\
\hline Number of institutions & 31 & 136 & 134 & 20 & 7 & 328 \\
\hline Frequency $(\%)$ & $9.5 \%$ & $41.5 \%$ & $40.9 \%$ & $6.1 \%$ & $2.1 \%$ & $100.0 \%$ \\
\hline \multicolumn{7}{|l|}{ Endovascular intervention } \\
\hline Annual cases & $<11$ & $11-50$ & $51-150$ & $151-300$ & $>300$ & Total \\
\hline Number of institutions & 90 & 120 & 71 & 32 & 15 & 328 \\
\hline Frequency $(\%)$ & $27.4 \%$ & $36.6 \%$ & $21.6 \%$ & $9.8 \%$ & $4.6 \%$ & $100.0 \%$ \\
\hline \multicolumn{7}{|l|}{ Kidney biopsy } \\
\hline Annual cases & $<11$ & $11-50$ & $51-100$ & $101-150$ & $>150$ & Total \\
\hline Number of institutions & 64 & 179 & 58 & 24 & 3 & 328 \\
\hline Frequency $(\%)$ & $19.5 \%$ & $54.6 \%$ & $17.7 \%$ & $7.3 \%$ & $0.9 \%$ & $100.0 \%$ \\
\hline \multicolumn{7}{|l|}{ PD catheter insertion } \\
\hline Annual cases & $<6$ & $6-10$ & $11-20$ & $21-40$ & $>40$ & Total \\
\hline Number of institutions & 214 & 67 & 37 & 7 & 3 & 328 \\
\hline Frequency $(\%)$ & $65.2 \%$ & $20.4 \%$ & $11.3 \%$ & $2.1 \%$ & $0.9 \%$ & $100.0 \%$ \\
\hline \multicolumn{7}{|l|}{ PD catheter removal } \\
\hline Annual cases & $<6$ & $6-10$ & $11-20$ & $21-40$ & $>40$ & Total \\
\hline Number of institutions & 285 & 37 & 4 & 1 & 1 & 328 \\
\hline Frequency $(\%)$ & $86.9 \%$ & $11.3 \%$ & $1.2 \%$ & $0.3 \%$ & $0.3 \%$ & $100.0 \%$ \\
\hline \multicolumn{7}{|l|}{ PD catheter unroofing } \\
\hline Annual cases & $<6$ & $6-10$ & $11-20$ & $21-40$ & $>40$ & Total \\
\hline Number of institutions & 325 & 3 & 0 & 0 & 0 & 328 \\
\hline Frequency $(\%)$ & $99.1 \%$ & $0.9 \%$ & $0.0 \%$ & $0.0 \%$ & $0.0 \%$ & $100.0 \%$ \\
\hline
\end{tabular}

328 institutions which performed all 4 procedures in their own institutions were included in this analysis. Annual procedure volume of VA surgery, endovascular interventions, kidney biopsies, PD catheter insertions, removal and unroofing were categorized, and each number and frequencies were presented $V A$ vascular access, $P D$ peritoneal dialysis

Table 3 Frequencies of procedure performance and involvement to procedure by nephrologists, non-nephrologists or their collaboration

\begin{tabular}{|c|c|c|c|c|c|c|}
\hline & $\begin{array}{l}\text { PD catheter } \\
\text { insertion }\end{array}$ & $\begin{array}{l}\text { PD catheter } \\
\text { removal }\end{array}$ & $\begin{array}{l}\text { PD catheter } \\
\text { unroofing }\end{array}$ & $\begin{array}{l}\text { Vascular } \\
\text { access surgery }\end{array}$ & $\begin{array}{l}\text { Endovascular } \\
\text { intervention }\end{array}$ & $\begin{array}{l}\text { Kidney } \\
\text { biopsy }\end{array}$ \\
\hline Total performing institutions & $250(76.2)$ & $250(76.2)$ & $250(76.2)$ & $316(96.3)$ & $290(88.4)$ & $309(94.2)$ \\
\hline Nephrologists ${ }^{\mathrm{a}}$ & $75(30.0)$ & $72(28.8)$ & $89(35.6)$ & $110(34.8)$ & $113(39.0)$ & $263(85.1)$ \\
\hline collaboration $^{\mathrm{a}}$ & $44(17.6)$ & $38(15.2)$ & $26(10.4)$ & $61(19.3)$ & $41(14.1)$ & $27(8.7)$ \\
\hline Non-nephrologists ${ }^{\mathrm{a}}$ & $131(52.4)$ & $140(56.0)$ & $135(54.0)$ & $145(45.8)$ & $136(46.9)$ & $19(6.1)$ \\
\hline
\end{tabular}

328 institutions answered all 4 procedures volume were included in this analysis. Table 3 shows frequencies of procedure performance and involvement to procedure by nephrologists, non-nephrologists or their collaboration. Each performance rates by any doctors were $96.3 \%$ for VA surgery (316/328 institutions), 94.2\% for kidney biopsy (309/328 institutions), 88.4\% for endovascular interventions (290/328 institutions) and $76.2 \%$ for PD access procedures (250/328 institutions)

Among 250 institutions which were offering PD access surgery by any doctors, frequencies of involvement to each PD access surgery by nephrologists, non-nephrologists or their collaboration were as follows: for PD catheter insertion, $30.0 \%(n=75)$ vs $52.4 \%(n=131)$ vs $17.6 \%$ $(n=44)$; for PD catheter removal, $28.8 \%(n=72)$ vs $56.0 \%(n=140)$ vs $15.2 \%(n=38)$; for PD catheter unroofing, $35.6 \%(n=89)$ vs $54.0 \%(n=135)$ vs $10.4 \%(n=26)$. Among non-nephrologists, surgeons $(24.0 \%, n=60 / 250)$ and urologists $(24.4 \%, n=61 / 250)$ were involved in higher degree of PD catheter insertions

Frequencies of involvement by nephrologists, non-nephrologists and their collaboration in VA surgery, endovascular interventions and kidney biopsies were as follows: for VA surgery, $34.8 \%(n=110)$ vs $45.8 \%(n=145)$ vs $19.3 \%(n=61$; total responses: 316$)$; for endovascular interventions, $39.0 \%(n=113)$ vs $46.9 \%(n=136)$ vs $14.1 \%(n=41$; total responses: 290$)$; and for kidney biopsy, $85.1 \%(n=263)$ vs $6.1 \%$ $(n=19)$ vs $8.7 \%(n=27$; total responses: 309$)$ (Fig. 1$)$

${ }^{a}$ Values represent number $(\%)$ of institutions in which indicated doctors were offering indicated procedure among each procedure performing institutions 


\section{Results}

\section{Responding rate}

Of the 534 Japanese certificated nephrology training institutions contacted, $236(44.2 \%)$ institutions responded to the initial letters in July 2014, and additional 96 (18.0\%) institutions responded to the follow-up letter in November 2014, resulting in responses from a total of $332(62.2 \%)$ institutions. We examined differences of responding rate among each Japanese region and found minimum responding rate was 54.6\% (18/33) in Chugoku region without significant differences. Though significant difference of responding rate was seen only in Hokkaido region [Hokkaido region 86.7\% $(13 / 15)$ vs the other regions $61.5 \%$ (319/519), $p<0.05]$, there was no significant differences among procedure performance, occupancy rates of nephrologists and procedure volume between Hokkaido region and the other regions.

\section{Distribution of annual procedure volume}

Table 2 shows the distribution of annual procedure volume of key procedures. 328 institutions which were performing all 4 procedures in their own institutions by any type of doctors were included in this analysis. Annual case numbers of PD catheter insertions were categorized, and numbers and frequencies were as follows: $<6$ cases, $65.2 \%(n=214$; total responses: 328$)$; $6-10$ cases, $20.4 \%(n=67) ; 11-20$ cases, $11.3 \%(n=37) ; 21-40$ cases, $2.1 \%(n=7)$; and $>40$ cases, $0.9 \%(n=3)$. The majority of institutions $(65.2 \%)$ performed $<6$ cases annually by any doctors.

Annual case numbers of PD catheter removal were categorized, and numbers and frequencies were as follows:
$<6$ cases, $86.9 \%(n=285$; total responses: 328$) ; 6-10$ cases, $11.3 \%(n=37) ; 11-20$ cases, $1.2 \%(n=4) ; 21-40$ cases, $0.3 \%(n=1)$; and $>40$ cases, $0.3 \%(n=1)$. The majority of institutions (86.9\%) performed $<6$ cases annually by any doctors.

Annual case numbers of PD catheter unroofing were categorized, and numbers and frequencies were as follows: $<6$ cases, $99.1 \%(n=325$; total responses: 328$)$; $6-10$ cases, $0.9 \%(n=3)$; and $>10$ cases, $0 \%(n=0)$. The majority of institutions (99.1\%) performed $<6$ cases annually by any doctors.

Annual case numbers of VA surgery were categorized, and numbers and frequencies were as follows: $<11$ cases, 9.5\% ( $n=31$; total responses: 328$)$; $11-50$ cases, $41.5 \%$ $(n=136) ; \quad 51-150$ cases, $40.9 \% \quad(n=134) ; 151-300$ cases, $6.1 \%(n=20)$; and $>300$ cases, $2.1 \%(n=7)$. The majority of institutions (82.4\%) performed VA surgery $11-150$ cases per year by any doctors.

Annual numbers of endovascular interventions were categorized, and numbers and frequencies were as follows: $<11$ cases, $27.4 \%$ ( $n=90$; total responses: 328$) ; 11-50$ cases, $36.6 \%(n=120)$; $51-150$ cases, $21.6 \%(n=71)$; 151-300 cases, $9.8 \%(n=32)$; and $>300$ cases, $4.6 \%$ $(n=15)$. The majority of institutions $(64.0 \%)$ performed endovascular interventions $<51$ cases annually by any doctors.

Annual numbers of kidney biopsies were categorized, and number and frequencies were as follows: $<11$ cases, $19.5 \%$ ( $n=64$; total responses: 328$) ; 11-50$ cases, $54.6 \%$ $(n=179) ; 51-100$ cases, $17.7 \%(n=58) ; 101-150$ cases, $7.3 \%(n=24)$; and $>150$ cases, $0.9 \%(n=3)$. Over half of institutions (54.6\%) performed 11-50 kidney biopsies annually by any doctors.
Fig. 1 Institutions were selected and included in each analysis. Each inclusion criteria and included institution number for indicated Figures and Tables are showing

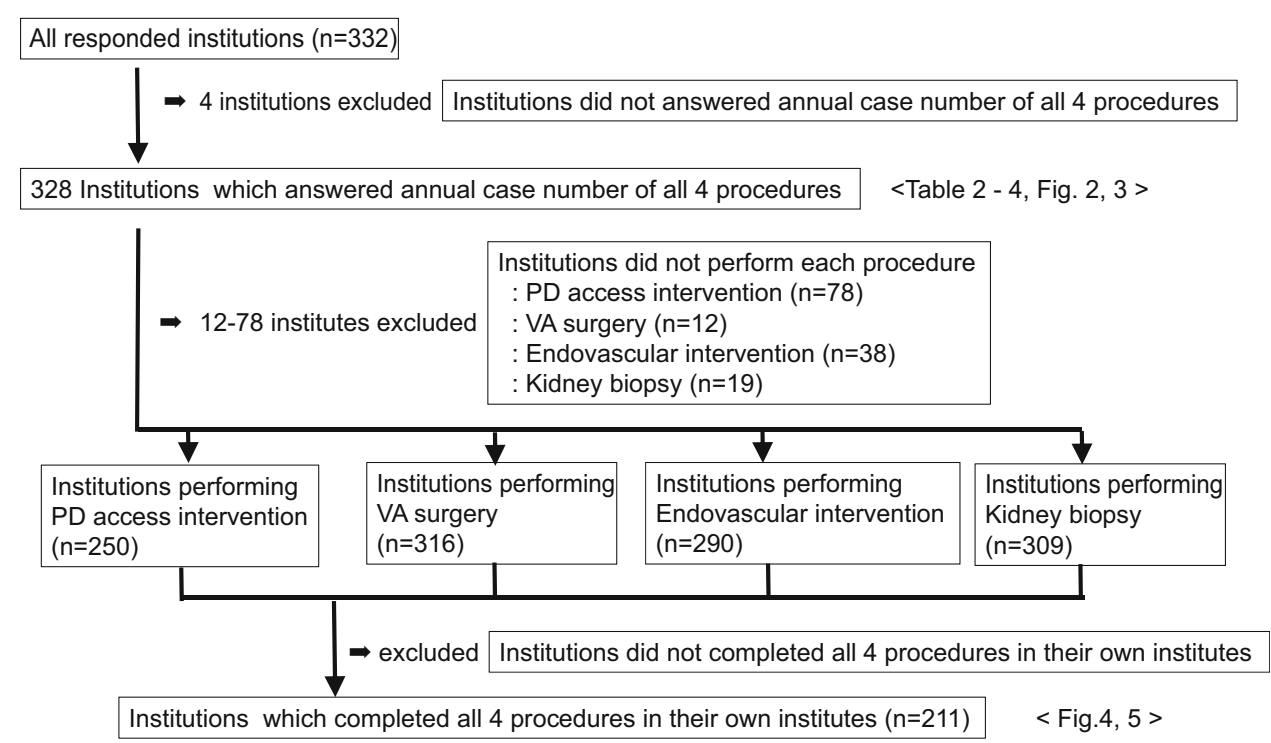




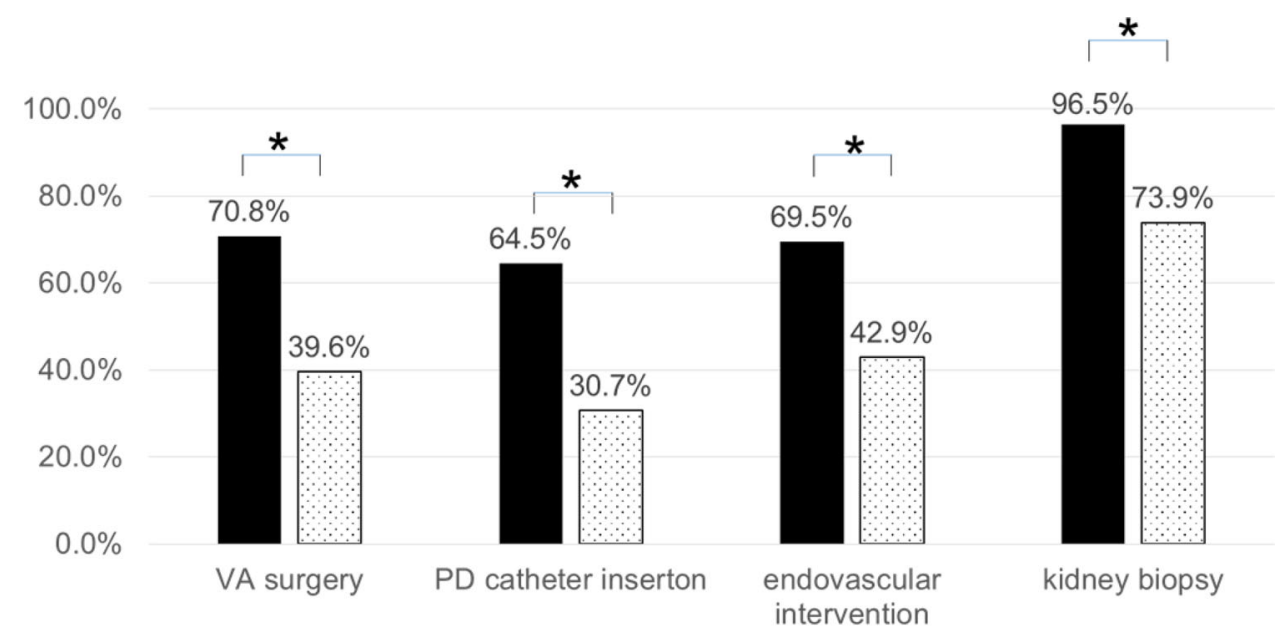

- High volume center

․․ow volume center

Fig. 2 Differences of nephrologist involvement levels between high and low volume center. Frequencies of nephrologist involvement between high and low volume center were $70.8 \%$ (92/130) and 39.6\% (36/91), $p<0.0001$ for $>50$ cases and not more than 50 cases year of VA surgery, $64.5 \%(69 / 107)$ and $30.7 \%$ (35/114), $p<0.0001$ for $>5$ cases and no more than 5 cases per year of PD catheter insertion,

\section{Frequencies of procedure performance} and involvement to procedure by nephrologists, nonnephrologists or their collaboration

328 institutions answered all 4 procedures volume and were included in this analysis. Table 2 shows frequencies of procedure performance and involvement to procedure by nephrologists, non-nephrologists or their collaboration. Each performance rates by any doctors were $96.3 \%$ for VA surgery (316/328 institutions), 94.2\% for kidney biopsy (309/328 institutions), $88.4 \%$ for endovascular interventions (290/328 institutions), and $76.2 \%$ for PD access procedures (250/328 institutions).

\section{Comparison of sharing rates of procedure performance by nephrologists, 1 non-nephrologists, and both acting cooperatively}

Among 250 institutions which were offering PD access surgery by any doctors, frequencies of involvement to each PD access surgery by nephrologists, non-nephrologists or their collaboration were as follows: for PD catheter insertion, $30.0 \%(n=75)$ vs $52.4 \%(n=131)$ vs $17.6 \%(n=44)$; for PD catheter removal, $28.8 \%$ $(n=72)$ vs $56.0 \%(n=140)$ vs $15.2 \%(n=38)$; for PD catheter unroofing, $35.6 \% \quad(n=89)$ vs $54.0 \%$ $(n=135)$ vs $10.4 \%(n=26)$. Among non-nephrologists, surgeons $(24.0 \%, n=60 / 250)$ and urologists (24.4\%, $n=61 / 250)$ were involved in higher degree of $\mathrm{PD}$ catheter insertions.
$69.5 \%(66 / 95)$ and $42.9 \%$ (54/126), $p<0.0001$ for $>50$ cases and not more than 50 cases per year of endovascular intervention, $96.5 \%$ $(191 / 198)$ and $73.9 \%(17 / 23), p<0.0001$ for $>10$ cases and not more than 10 cases per year of kidney biopsy, respectively. Values represent the percentage of nephrologist involvement. ${ }^{*} p<0.01$

Frequencies of involvement by nephrologists, nonnephrologists and their collaboration in VA surgery, endovascular interventions and kidney biopsies were as follows: for VA surgery, $34.8 \%(n=110)$ vs $45.8 \%$ $(n=145)$ vs $19.3 \%(n=61$; total responses: 316$)$; for endovascular interventions, $39.0 \%(n=113)$ vs $46.9 \%$ ( $n=136)$ vs $14.1 \%$ ( $n=41$; total responses: 290$)$; and for kidney biopsy, $85.1 \%(n=263)$ vs $6.1 \%(n=19)$ vs $8.7 \%$ ( $n=27$; total responses: 309 ) (Fig. 1$)$.

Among non-nephrologists, cardiac surgeons (19.0\%, $n=60 / 316)$, urologists $(13.0 \%, n=41 / 316)$, surgeons $(8.9 \%, n=28 / 316)$ and others $(5.1 \%, n=16 / 316)$ performed VA surgery. Radiologists $(23.1 \%, n=67 / 290)$, cardiac surgeons $(11.4 \%, \quad n=33 / 290)$, cardiologists $(7.6 \%, n=22 / 290)$, surgeons $(1.7 \%, n=5 / 290)$ and others $(3.1 \%, n=9 / 290)$ performed endovascular interventions. Urologists $(4.9 \%, n=15 / 309)$ and others $(1.3 \%$, $n=4 / 309$ ) performed kidney biopsies.

$68.9 \%(226 / 328)$ institutions could complete all 4 procedures in their own institutions by any doctors. And $22.9 \%$ (75/328) institutions could complete all 4 procedures by nephrologists (including nephrologists in cooperative action with non-nephrologists). The resultant $46.0 \%$ (151/328) institutions needed other specialists to complete all 4 procedures.

\section{Methods of native kidney biopsy}

In this survey, we also investigated method of kidney biopsy in Japanese certificated adult nephrology training 


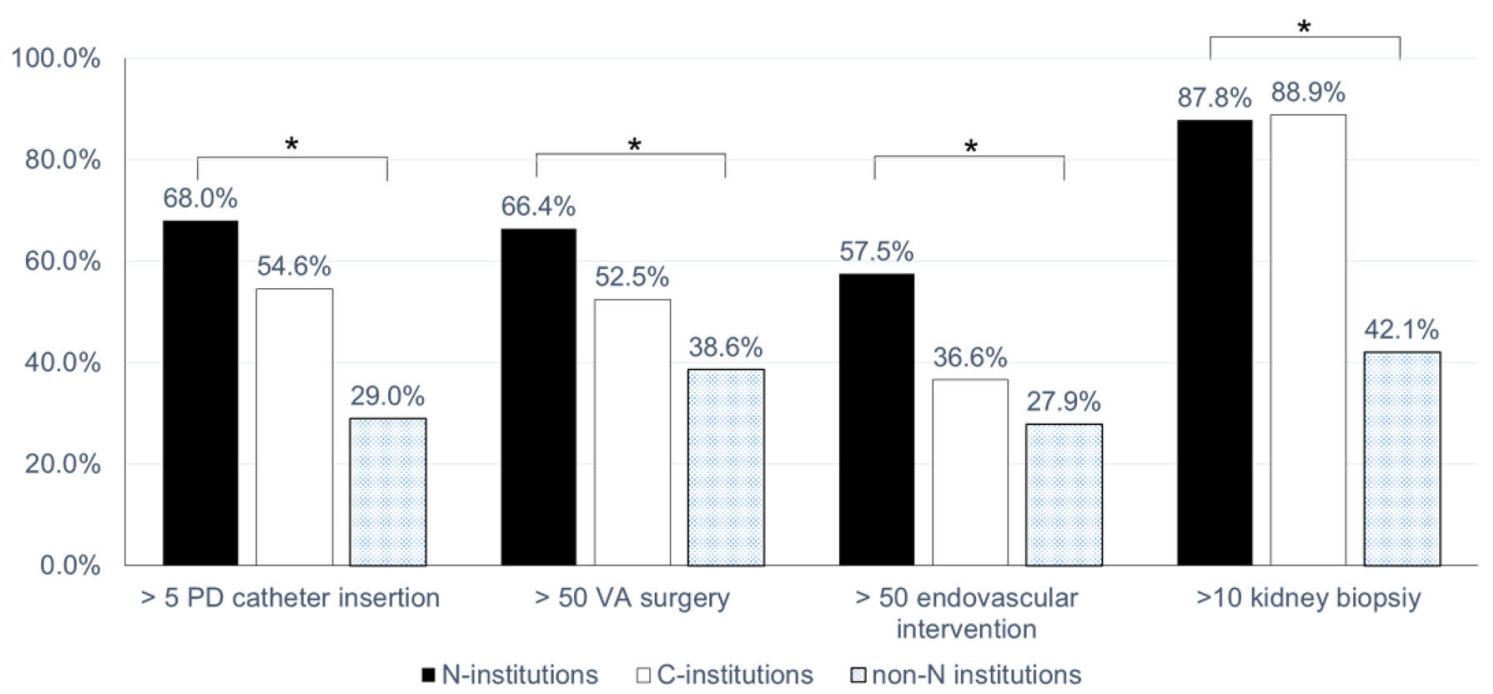

Fig. 3 Associations between procedure manager and procedure volume. Associations between procedure manager and procedure volume were analyzed. Institutions number which were performing each procedure included in this analysis were as follows: PD $(n=250)$, VA surgery $(n=316)$, endovascular intervention $(n=290)$ and kidney biopsy $(n=309)$. Among $\mathrm{N}$-institutions, $\mathrm{C}$-institutions and non-N-institutions, the percentages of institutions that performed the indicated annual volumes were compared as follows: $>5$ PD catheter insertions [68.0\% (51/75) vs 54.6\% (24/44) vs $29.0 \%$ (38/131), total analyzed institutions 250 ], $>50$ VA surgery

institutions. Kidney biopsy (total responded institutions: 309) was performed by ultrasound (US)-guided in $99.0 \%$ $(n=306) .92 .2 \%(n=285)$ used US-guided procedures alone, $6.1 \%(n=19)$ used both US-guided or open biopsy, and $0.6 \%(n=2)$ used either US- or X-ray-guided procedures. The remaining institutions used open biopsy alone $(0.6 \%, n=2)$ or some other method details unknown $(0.3 \%, n=1)$. There were no institutions performing $\mathrm{X}$-ray-guided kidney biopsy alone.

\section{Differences of nephrologist involvement levels between high and low volume center}

To clarify association between frequencies of nephrologist involvement to each intervention and procedure volume, we compared the frequencies of nephrologist involvement between high volume center and low volume center in each 4 procedure (Fig. 2). Frequencies of nephrologist involvement between high and low volume center were $70.8 \% \quad(92 / 130)$ and $39.6 \%$ (36/91), $p<0.01$ for $>50$ cases and no more than 50 cases year of VA surgery, $64.5 \%(69 / 107)$ and $30.7 \%$ (35/114), $p<0.01$ for $>5$ cases and no more than 5 cases per year of PD catheter insertion, $69.5 \%(66 / 95)$ and $42.9 \%$ (54/126), $p<0.01$ for $>50$ cases and no more than 50 cases per year of endovascular intervention, $96.5 \%$ $(191 / 198)$ and $73.9 \%(17 / 23), p<0.01$ for $>10$ cases
[66.4\% (73/110) vs $52.5 \%(32 / 61)$ vs $38.6 \%(56 / 145)$, total analyzed institutions 316], $>50$ endovascular interventions [57.5\% (65/113) vs $36.6 \%(15 / 41)$ vs $27.9 \%$ (38/136), total analyzed institutions 290], and $>10$ kidney biopsies $[85.1 \%(231 / 263)$ vs $88.9 \%(24 / 27)$ vs $42.1 \%$ (8/ 19), total analyzed institutions 309]. Cochran-Armitage analyses demonstrated significant increases in procedure volume with greater management by nephrologists. Values represent the percentage of institutions which performed indicated procedure volume. $* p<0.01$ for trend. $P D$ peritoneal dialysis, $V A$ vascular access

and no more than 10 cases per year of kidney biopsy, respectively.

Thus, there were significant differences in the frequencies of nephrologist involvement for clinical intervention among the groups categorized by the number of volume of cases. And higher volume centers were offering significant higher frequencies of nephrologist involvement in all 4 procedures.

\section{Associations between the levels of nephrologist involvement and procedure volume}

Next, to examine whether interventional nephrologists have the potential to increase procedure volumes as nephrologists get more deeply involved in each procedure, we analyzed associations between levels of independence from non-nephrologists and annual procedure volume. Frequencies of institutions that performed $>5$ PD catheter insertions, $>50$ VA surgery, $>50$ endovascular interventions and $>10$ kidney biopsies annually were compared among $\mathrm{N}$-institutions, $\mathrm{C}$-institutions and non$\mathrm{N}$-institutions (Fig. 3). Institutions which were performing each procedure were included in this analysis and each institution number was as follows: PD catheter insertion $(n=250)$, VA surgery $(n=316)$, endovascular intervention $(n=290)$ and kidney biopsy $(n=309)$.

$>5$ PD catheter insertions were performed in $68.0 \%$ of $\mathrm{N}$-institutions (51/75), $54.6 \%$ of C-institutions (24/44) and $29.0 \%$ of non- $\mathrm{N}$-institutions (38/131) among 250 


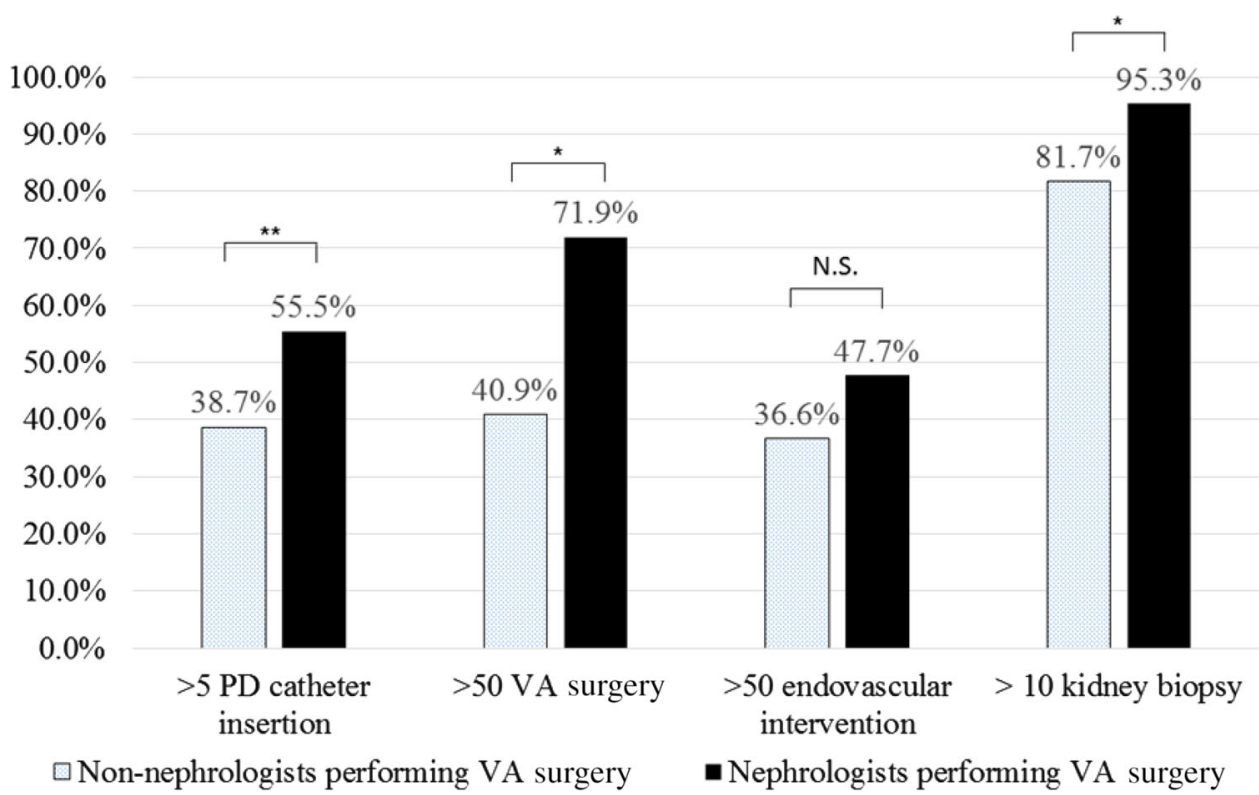

Fig. 4 Comparison of the annual procedure volume between institutions in which VA surgery was managed by nephrologists and nonnephrologists. In this analysis, we included only 221 institutions which completed all 4 procedures in their own institutions (Fig. 1) and compared categorized procedure volume between 128 institutions in which nephrologist participated to VA surgery and 93 institutions in which VA surgery was performed by non-nephrologists alone. Each frequency of institutions performing indicated procedure volume were as follows: $>5$ PD catheter insertion, 55.5\% (nephrologists managing institutions) vs $38.7 \%$ (non-nephrologists managing

institutions that were performing PD access procedures. Over 50 VA surgery were performed annually in $66.4 \%$ of $\mathrm{N}$-institutions (73/110), $52.5 \%$ of C-institutions (32/61) and $38.6 \%$ of non-N-institutions (56/145) among 316 institutions that were performing VA surgery. Over 50 endovascular interventions were performed annually in $57.5 \%$ of $\mathrm{N}$-institutions (65/113), 36.6\% of C-institutions (15/41) and $27.9 \%$ of non-N-institutions (38/136) among 290 institutions that were performing endovascular interventions. More than 10 kidney biopsies annually were performed in $85.1 \%$ of institutions (263/309), comprising $87.8 \%$ of N-institutions (231/263), $88.9 \%$ of C-institutions (24/27) and $42.1 \%$ of non-N-institutions (8/19).

Cochran-Armitage analysis showed annual numbers of PD catheter insertions, VA surgery, endovascular interventions and kidney biopsies significantly increased in a stepwise manner from non- $\mathrm{N}$-institutions to $\mathrm{C}$-institutions to $\mathrm{N}$-institutions as nephrologist involved more as follows: $>5$ PD catheter insertions/year, $n=250(p<0.0001)$; $>50$ VA surgery/year, $n=316 \quad(p=0.0055) ;>50$ endovascular interventions/year, $n=290 \quad(p=0.0083)$; and $>10$ kidney biopsies/year, $n=309 \quad(p=0.0001)$. These analysis suggested procedure volume may increase with the levels of independence from non-nephrologists. institutions), $p=0.0138 ;>50$ VA surgery, $71.9 \%$ (nephrologists managing institutions) vs $40.9 \%$ (non-nephrologists managing institutions), $\quad p<0.0001 ;>50$ endovascular interventions, $47.7 \%$ (nephrologists managing institutions vs $36.6 \%$ non-nephrologists managing institutions), $p=0.0999$; and $>10$ kidney biopsy, $95.3 \%$ (nephrologists managing institutions vs $81.7 \%$ non-nephrologists managing institutions), $p=0.0011$, respectively. Values represent the percentage of institutions which performed indicated procedure volume. ${ }^{*} p<0.01 .{ }^{*} p<<0.05$

\section{Comparison of the annual procedure volume between institutions in which VA surgery was managed by nephrologists and non- nephrologists}

When nephrologists acquire a specific procedure, whether it has positive effects on the other procedure volume is worth examination. In this analysis, we included only 221 institutions which completed all 4 procedures in their own institutions (Fig. 1) and compared categorized procedure volume between 128 institutions in which nephrologist participated to VA surgery and 93 institutions in which VA surgery was performed by non-nephrologists alone (Fig. 4). Each frequency of institutions performing indicated procedure volume were as follows: for $>5$ PD catheter insertion, 55.5 vs $38.7 \%, p=0.0138$; for $>50$ VA surgery, 71.9 vs $40.9 \%, p<0.0001$; for $>50$ endovascular interventions, 47.7 vs $36.6 \%, p=0.0999$; and for $>10$ kidney biopsy, 95.3 vs $81.7 \%, p=0.0011$, respectively.

Thus, nephrologists performing VA surgery associated with procedure volume increase in both VA surgery, PD catheter insertion and kidney biopsy. 


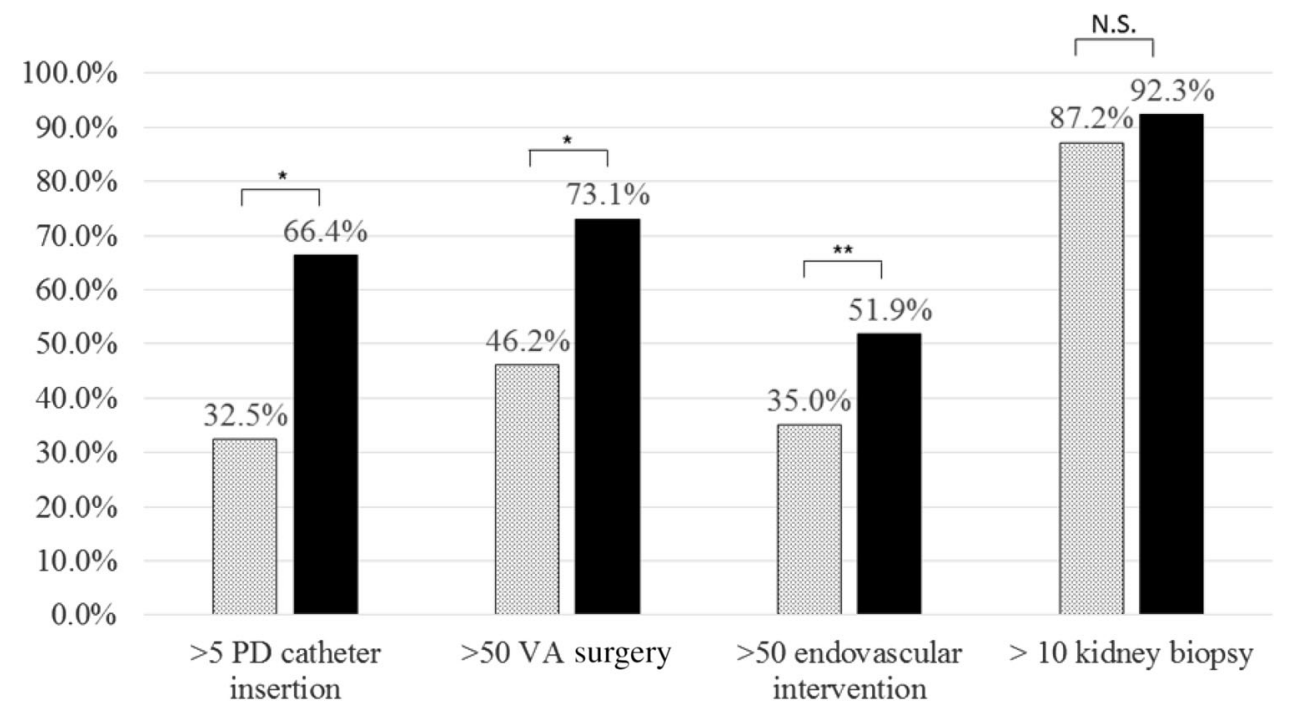

- Non-nephrologists performing PD catheter inserion

- Nephrologists performing PD catheter inserion

Fig. 5 Comparison of the annual procedure volume between institutions in which PD catheter insertion was managed by nephrologists and non-nephrologists. We included only 221 institutions which performed all 4 procedures in their own institutions (Fig. 1) and compared categorized procedure volume between 117 institutions in which nephrologist participated in PD catheter insertion surgery and 104 institutions in which PD catheter insertion was performed by nonnephrologists alone (Fig. 5). Each frequency of institutions performing indicated procedure volume were as follows: $>5$ PD catheter insertion, $66.4 \%$ (nephrologists managing institutions) vs $32.5 \%$ (non-

\section{Comparison of the annual procedure volume between institutions in which PD catheter insertion was managed by nephrologists and non- nephrologists}

As well as the above analysis, we included only 221 institutions which performed all 4 procedures in their own institutions (Fig. 1) and compared categorized procedure volume between 117 institutions in which nephrologist participated in PD catheter insertion surgery and 104 institutions in which PD catheter insertion was performed by non-nephrologists alone (Fig. 5). Each frequency of institutions performing indicated procedure volume were as follows: for $>5 \mathrm{PD}$ catheter insertion, 66.4 vs $32.5 \%$, $p<0.01$; for $>50 \mathrm{VA}$ surgery, 73.1 vs $46.2 \%, p<0.01$; for $>50$ endovascular interventions, 51.9 vs $35.0 \%, p=0.01$; and for $>10$ kidney biopsy, 92.3 vs $87.2 \%, p=0.21$, respectively.

Thus, when nephrologists perform PD catheter insertion, it may have positive effect on procedure volume increases in VA surgery and endovascular intervention. Additive effect of interventional nephrology on both penetration and volume increase in the other procedures was suggested in these analysis. nephrologists managing institutions), $p<0.0001 ;>50$ VA surgery, $73.1 \%$ (nephrologists managing institutions) vs $46.2 \%$ (non-nephrologists managing institutions), $p<0.0001 ;>50$ endovascular interventions, $51.9 \%$ (nephrologists managing institutions) vs $35.0 \%$ (nonnephrologists managing institutions), $p=0.0114$; and $>10$ kidney biopsy, $92.3 \%$ (nephrologists managing institutions) vs $87.2 \%$ (nonnephrologists managing institutions), $p=0.2127$, respectively. Values represent the percentage of institutions which performed indicated procedure volume. ${ }^{*} p<0.01$. ${ }^{* *} p<0.05$

\section{Discussion}

Surprisingly, main managers of all 4 procedures were nephrologists in Japan. All procedure volume increased as nephrologists become more involved. Acquisition of one specific procedure by nephrologist associated with increase in not only this specific procedure volume, but also the other procedure volume.

Thus, this first survey revealed Japanese interventional nephrology was active and Japanese nephrologists were coming in first manager of all 4 procedures in certificated Japanese nephrology training institutions and were taking the lead to perform VA surgery, endovascular intervention and PD access surgery in about a half of institutions in Japan. No other countries have been reported to offer more nephrologists' involvement to these procedures like Japan. On the other hand, only $22.9 \%$ (75/328) of institutions could complete all 4 procedures by nephrologists (in cooperative action with non-nephrologists), indicating that majority of nephrology fellows could rarely train all 4 procedures even in Japanese certificated nephrology training institutions.

Nephrologists' participation to VA surgery did not only associate with surgical volume increase in VA surgery, but 
also associated with procedure volume increase for PD catheter insertion and kidney biopsy. And nephrologists' participation to PD catheter insertion associated with surgical volume increase in not only PD catheter insertion, but also both VA surgery and endovascular intervention. Thus, acquisition of one interventional procedure by nephrologists may enhance skill acquisition and volume increase in the other procedures. This chain reaction will activate interventional nephrology in each institution and may promote fellows to select nephrology as a carrier choice.

Japanese certificated nephrology training institutions were offering VA surgery, kidney biopsy, and endovascular intervention with higher performance rates of over $88.4 \%$ by any doctors. On the other hand, performance rate of PD access surgery by any doctors was relatively lower (76.2\%) and non-nephrologists managed over half of PD access surgery, revealing many young nephrologists could not train PD access surgery even in certificated nephrology training institutions.

Present study revealed main manager of VA surgery was nephrologist, followed by cardiac surgeon, urologists and surgeon in Japan. 54.1\% of nephrology training institutions were performing VA surgery by nephrologists alone $(34.8 \%)$ or with the help of a non-nephrologist (19.3\%), relatively high rates compared to reports from both the United States and Europe.

Arteriovenous fistula (AVF) established by nephrologists represented only $35 \%$ in Europe and under $11 \%$ in the United States [11, 12]. Beathard et al. reported nephrologist occupancy responsibility in only $25 \%$ of VA procedures and endovascular interventions in the United States, with surgeons $(35 \%)$ and radiologists $(30 \%)$ representing large majorities [13]. In Italy, approximately $80 \%$ of dialysis centers have performed AVF by nephrologists alone $(48.8 \%)$ or with the help of a surgeon $(26.4 \%)$ [14]. Thus, nephrologist-managed VA surgery is more frequently performed in Japan than the United States and Europe, but is less frequently performed than Italy.

To date, HD access surgery by nephrologists and its main effects have also been reported [12, 15-17]. VA surgery and endovascular intervention by nephrologists can improve access outcomes [18] and timely detection of malfunctions in vascular access, increases the survival of vascular access [19] and use of AVF, and decreases HD catheter utilization [20]. In these regards, frequent practice of interventional nephrology may contribute to good survival of HD patients in Japan [21].

In this survey, $76.2 \%$ institutions answered they could offer PD access surgery by any doctors. But over 10 cases/ annually of PD catheter insertion were performed by only $14.3 \%$ institutions in Japan, relative fewer than $23 \%$ in USA (23\%) [22]. Contrastingly, nephrologists offer PD surgery in $47.6 \%$ (119/250) institutions in Japan, relative higher than $14 \%$ in USA [1] in which non-nephrologists almost offer PD access surgery. This means non-nephrologists in USA were offering PD catheter insertion surgery more frequently than non-nephrologists in Japan.

This poor surgical volume of PD catheter insertion by non-nephrologists is a characteristic in Japan and may cause the poor penetration rate of PD in Japan [23, 24]. So, acquisition of $\mathrm{PD}$ catheter insertion procedure by nonnephrologists in non-N institutions may lead to increase in PD case number in Japan.

Several reports described PD catheter insertion by nephrologists and the effects on clinical nephrology, such as utilization of PD [25-28] or prevention of catheter-related infection [29]. It may be a good idea to impose obligation to participate in the PD access procedure on the non-nephrologists receiving certified member license of Society for Dialysis.

Performance rates for kidney biopsy performed by any type of doctor were 94.2\% (309/328 institutions) in present study, broadly comparable to the high rate in the United States (99\%) [1]. Additionally, 99.0\% (306/309 institutions) of institutions performed US-guided kidney biopsy in present study, more frequent than the $42 \%$ in the United States in 2008 [1].

\section{Limitations}

This study involved several limitations. First, participation was voluntary, with $37.8 \%$ of directors were not responding. Second, we could not analyze details about which kinds of VA surgery and endovascular intervention were performed in responding institutions. Third, no attempt was made to verify the accuracy of the responses. In this regard, other surveys conducted in this field were similar to the other survey [30, 31]. Forth, this study used a cross-sectional design so that it cannot be demonstrated that nephrologists could increase all procedure volume and acquisition of a specific procedure by nephrologists could increase the other procedure volume.

\section{Conclusion}

This survey offers the first comprehensive picture of interventional nephrology in Japanese nephrology training institutions. Main manager of all 4 procedures was nephrologist in Japan. All procedure volume increased as nephrologists become more involved. Acquisition of one specific procedure by nephrologist associated with increase in not only this specific procedure volume, but also the other procedure volume.

Acknowledgements We are grateful to the directors of all institutions that provided responses. 


\section{Compliance with ethical standards}

Conflict of interest The authors have declared that no conflict of interest exists.

Ethical approval The ethics committee for clinical research at Jikei University School of Medicine approved all protocols in this study [permission no. 26-003 (7508)].

Funding This research received no specific grant from any funding agency in the public, commercial, or not-for-profit sectors.

Informed consent No consent form is needed for questionnaire survey of physicians: consent is implied by returning the questionnaire.

Open Access This article is distributed under the terms of the Creative Commons Attribution 4.0 International License (http://creative commons.org/licenses/by/4.0/), which permits unrestricted use, distribution, and reproduction in any medium, provided you give appropriate credit to the original author(s) and the source, provide a link to the Creative Commons license, and indicate if changes were made.

\section{References}

1. Berns JS, O'Neill WC. Performance of procedures by nephrologists and nephrology fellows at U.S. nephrology training programs. Clin J Am Soc Nephrol. 2008;3(4):941-7.

2. Jhaveri KD, Sparks MA, Shah HH, Khan S, Chawla A, Desai T, Iglesia E, Ferris M, Parker MG, Kohan DE. Why not nephrology? A survey of US internal medicine subspecialty fellows. Am J Kidney Dis. 2013;61(4):540-6.

3. Parker MG, Ibrahim T, Shaffer R, Rosner MH, Molitoris BA. The future nephrology work force: will there be one? Clin J Am Soc Nephrol. 2011;6(6):1501-6.

4. Riella MC. Challenges in interventional nephrology. Contrib Nephrol. 2005;149:131-7.

5. Ash S. Guidelines for training, certification, and accreditation for hemodialysis vascular access and endovascular procedures. American Society of Diagnostic and Interventional Nephrology. Semin Dial. 2003;16(2):173-6.

6. Nascimento MM, Chula D, Campos R, Nascimento D, Riella MC. Interventional nephrology in Brazil: current and future status. Semin Dial. 2006;19(2):172-5.

7. Baez R, Betancourt J, Diaz HJ, Monserrate J, Ramírez T, Gorrochategui M, Rivera Bermudez C, Torre Leon F, Cangianoa JL. Interventional nephrology in Puerto Rico: a four year experience. Bol Asoc Med Puerto Rico. 2015;107(1):8-11.

8. Roy-Chaudhury P, Yevzlin A, Bonventre JV, Agarwal A, Almehmi A, Besarab A, Dwyer A, Hentschel DM, Kraus M, Maya I, Pflederer T, Schon D, Wu S, Work J. Academic interventional nephrology: a model for training, research, and patient care. Clin J Am Soc Nephrol. 2012;7(3):521-4.

9. Andreoli SP, West KW, Grosfeld JL, Bergstein JM. A technique to eradicate tunnel infection without peritoneal dialysis catheter removal. Perit Dial Int. 1983;3:S4-5.

10. Terawaki H, Nakano H, Ogura M, Kadomura M, Hosoya T, Nakayama M. Unroofing surgery with en bloc resection of the skin and tissues around the peripheral cuff. Perit Dial Int. 2013;33(5):573-6.

11. Pisoni RL, Young EW, Mapes DL, Keen ML, Port FK. Vascular access use in the U.S., Europe and Japan: results from the dialysis outcomes and practice pattern study. Nephrol News Issues. 2003; 17(38-43):47.
12. Stanziale R, Lodi M, D'Andrea E, D'Andrea T. Vascular access for hemodialysis: experience of a team of nephrologists. Hemodial Int. 2008;12(3):328-30.

13. Beathard GA, Schon D. Joint Coding Committee, American Society of Diagnostic and Interventional Nephrology and the Renal Physicians Association: ASDIN news and update. Semin Dial. 2009;22:312-7.

14. Bonucchi D, D’Amelio A, Capelli G, Albertazzi A. Management of vascular access for dialysis: an Italian survey. Nephrol Dial Transplant. 1999;14(9):2116-8.

15. Mishler R, Yevzlin AS. Outcomes of arteriovenous fistulae created by a U.S. interventional nephrologist. Semin Dial. 2010;23(2):224-8.

16. Mishler R, Yang Z, Mishler E. Arteriovenous fistula creation by nephrologist access surgeons worldwide. Adv Chronic Kidney Dis. 2015;22(6):425-30.

17. Doi S, Masaki T. Vascular access intervention by a nephrologist in Hiroshima. J Vasc Access. 2015;16(Suppl 10):S58-61.

18. Fumagalli G, De Pietro S, Migliori M, Ferrandello FP, Trovato F, Donadio C, Panichi V. Outcomes of vascular access care and surgery managed by interventional nephrologists: a twelve-year experience. Blood Purif. 2016;42(2):111-20.

19. Malovrh M. Vascular access creation and care should be provided by nephrologists. J Vasc Access. 2015;16(Suppl 9):S20-3.

20. Haq NU, Sayeed S, Ali SA. Impact of training in interventional nephrology on hemodialysis vascular access types. Semin Dial. 2009;22(1):90-2.

21. Wakasugi M, Kazama JJ, Narita I. Mortality trends among Japanese dialysis patients, 1988-2013: a joinpoint regression analysis. Nephrol Dial Transplant. 2016;31(9):1501-7.

22. Mujais S, Story K. Peritoneal dialysis in the US: evaluation of outcomes in contemporary cohorts. Kidney Int Suppl. 2006;103:S21-6.

23. Fresenius Medical Care ESRD Patients in 2013. A global perspective. http://www.visionfmc.com/files/ESRD_Patients_in_ 2013.pdf. Accessed 10 Apr 2016.

24. Masakane I, Nakai S, Ogata S, Kimata N, Hanafusa N, Hamano T, Wakai K, Wada A, Nitta K. An Overview of regular dialysis treatment in Japan (As of 31 December 2013). Ther Apher Dial. 2015;19:540-74.

25. Asif A, Pflederer TA, Vieira CF, Diego J, Roth D, Agarwal A. Does catheter insertion by nephrologists improve peritoneal dialysis utilization? A multicenter analysis. Semin Dial. 2005;18:157-60.

26. Sampathkumar K, Mahaldar AR, Sooraj YS, Ramkrishnan M, Ajeshkumar, Ravichandran R. Percutaneous CAPD catheter insertion by a nephrologist versus surgical placement: a comparative study. Indian J Nephrol. 2008;18(1):5-8.

27. Ros-Ruiz S, Alonso-Esteve Á, Gutiérrez-Vílchez E, Rudas-Bermúdez E, Hernández D. The impact of interventional nephrologists on the growth of a peritoneal dialysis program: long-term, single-center experience. Nefrologia. 2016;36(1):19-23.

28. Ng EK, Goh BL, Chew SE, Tan CC, Ching CH, Sha' ariah MY, Rozina MG. Multicenter analysis on the impact of nephrologistinitiated catheter insertion program on peritoneal dialysis penetration. Semin Dial. 2012;25(5):569-73.

29. Taro Y, Yoshimoto A, Kawakita M, Ueta H, Toda N, Utsunomiya $\mathrm{N}$, Muguruma K, Segawa T, Suzuki T. Impact of the inclusion of a nephrologist on the surgical team for peritoneal catheter insertion. Perit Dial Int. 2012;32(3):346-8.

30. Tape TG, Wigton RS, Blank LL, Nicolas JA. Procedural skills of practicing nephrologists: a national survey of 700 members of the American College of Physicians. Ann Intern Med. 1990;113:392-7.

31. Kimmel PL, Bosch JP. Effectiveness of renal fellowship training for subsequent clinical practice. Am J Kidney Dis. 1991;18:249-56. 